\title{
CONSORCIO MICROBIANO AUTÓCTONO PARA EL TRATAMIENTO DE AGUAS CONTAMINADAS CON GASOIL DEL PUERTO DE ISLA DE TOAS (VENEZUELA)
}

\author{
AUTOCHTHONOUS MICROBIAL CONSORTIUM FOR DIESEL \\ CONTAMINATED WATER TREATMENT FROM TOAS ISLAND \\ HARBOR (VENEZUELA)
}

Laugeny Chiquinquirá Díaz-Borrego*

Julio César Marín Leal ${ }^{*}$

Desiree Alejandra Alburgue Díaz ${ }^{* * *}$

Sedolfo José Carrasquero Ferrer***

Ever Darío Morales Avendaño****

Fecha de recepción: 2 de marzo de 2017

Fecha de revisión: 29 de agosto de 2017

Fecha de aprobación: 18 de octubre de 2017

Cómo citar: L. C. Díaz Borrego, J. C. Marín Leal, D. A. Alburque Díaz, S. J. Carrasquero Ferrer, E. D. Morales Avendaño, "Consorcio microbiano autóctono para el tratamiento de aguas contaminadas con gasoil del puerto de Isla de Toas (Venezuela)," Ciencia e Ingeniería Neogranadina, vol. 28, no. 2, pp. 5-28. DOI: https://doi. org/10.18359/rcin. 2792

\footnotetext{
* Lcda., M. Sc., Dra., Profesora titular, Laboratorio de Microorganismos Fotosintéticos, Departamento de Biología, Facultad Experimental de Ciencias, Universidad del Zulia, Maracaibo 4001-A, estado Zulia, Venezuela. Correo electrónico: Idiaz@fec.luz.edu.ve. ORCID: 0000-0002-8263-081X. Autor para la correspondencia.

** Lcdo., M. Sc., Dr., Profesor titular, Departamento de Ingeniería Sanitaria y Ambiental (DISA), Escuela de Ingeniería Civil, Facultad de Ingeniería, Universidad del Zulia, Maracaibo 4001-A, estado Zulia, Venezuela. Correo electrónico:jmarin@fing.luz.edu.ve.ORCID:0000-0003-2770-5978

*** Ing., M. Sc., Asistente de investigación, Laboratorio de Microorganismos Fotosintéticos, Departamento de Biología, Facultad Experimental de Ciencias, Universidad del Zulia, Maracaibo 4001-A, estado Zulia, Venezuela. Correo electrónico: alburgued@hotmail.com. ORCID: 0000-0002-9867-9706

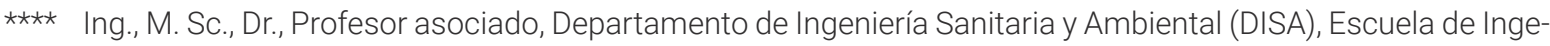
niería Civil, Facultad de Ingeniería, Universidad del Zulia, Maracaibo 4001-A, estado Zulia, Venezuela. Correo electrónico: scarrasquero@fing.luz.edu.ve. ORCID: 0000-0002-4725-963X

$\star \star \star \star \star$ Lcdo., M. Sc. Dr., Docente-investigador, Carrera de biología, Facultad de Ciencias Naturales, Universidad de Guayaquil, Guayaquil, provincia de Guayas, Ecuador. Correo electrónico: evermster@gmail.com. ORCID: 0000-0001-9006-4996
} 


\section{RESUMEN}

El tratamiento biológico de aguas contaminadas, mediante consorcios microbianos autóctonos, aprovecha las potencialidades metabólicas de grupos distintos de microorganismos para degradar y/o remover una amplia variedad de compuestos. Adicionalmente, las técnicas de bioestimulación y bioaumentación contribuyen a fortalecer las capacidades de estos procesos de biodegradación. El objetivo de este trabajo consistió en evaluar la utilización de un consorcio microbiano autóctono (Chlorella spp.-bacterias) para el tratamiento de aguas del puerto de Isla de Toas (Lago de Maracaibo, Venezuela), contaminadas con $1 \% \mathrm{v} / \mathrm{v}$ de gasoil. Para ello, se usaron dos tratamientos ( $\mathrm{T} 1$ : bioestimulado y $\mathrm{T} 2$ : bioaumentado) y un control por 70 días, a escala de $20 \mathrm{~L}$ y condiciones ambientales controladas. Durante los ensayos se monitorearon: temperatura, $\mathrm{pH}$, demanda química de oxígeno (DQO), nitrito, nitrato, nitrógeno total Kjeldahl, nitrógeno total ( $\mathrm{N}$-total), ortofosfato, fósforo total (P-total), hidrocarburos totales del petróleo (HTP), fracciones de hidrocarburos (SARA), densidad microalgal y bacteriana, y pigmentos fotosintéticos, de acuerdo con los métodos estandarizados. Los valores medios para la remoción de materia orgánica (DQ0), N-total y P-total, fueron: $23,3 \pm 2,3 ; 35,2 \pm 4,5$ y $64,6 \pm 4,8 \%$, de $27,6 \pm 1,64 ; 79,8 \pm 2,05$ y $87,7 \pm 1,95 \%$, y de $<0,1 ; 16,1 \pm 0,38$ y $44,7 \pm 1,18 \%$, para el control, T1 y T2, respectivamente. Las concentraciones finales de HTP estuvieron por encima del límite permisible de la normativa venezolana para descarga a cuerpos de aguas naturales, no obstante, se obtuvieron altas tasas de remoción de hidrocarburos saturados y aromáticos ( $>70 \%)$, particularmente en el tratamiento bioaumentado (T2). Los consorcios microbianos autóctonos poseen gran potencial para la biorrecuperación del agua del puerto de Isla de Toas, contaminada con hidrocarburos del petróleo, por lo cual se recomienda continuar investigando sobre esta tecnología de tratamiento.

Palabras Clave: bioaumentación, bioestimulación, degradación microbiana, hidrocarburos, metabolismo mixotrófico, tratamiento biológico.

\section{ABSTRACT}

The biological treatment of polluted water using autochthonous microbial consortia harnesses the metabolic potential of different groups of microorganisms to degrade and/or remove a wide variety of compounds. Additionally, biostimulation and bioaugmentation techniques contribute to enhancing the capabilities of these biodegradation processes. The objective of this paper was to evaluate the use of an autochthonous microbial consortium (Chlorella spp.-bacteria) to treat water at the Toas Island harbor (Maracaibo Lake, Venezuela), polluted by $1 \% \mathrm{v} / \mathrm{v}$ diesel. For this, two treatments (T1: biostimulated and T2: bioaugmented) and a control were used for 70 days, at a scale of $20 \mathrm{~L}$ and under controlled environmental conditions. During the tests, temperature, $\mathrm{pH}$, chemical oxygen demand (COD), nitrite, nitrate, total Kjeldahl nitrogen, total nitrogen (TN), orthophosphate, total phosphorus (TP), total petroleum hydrocarbons (TPH), hydrocarbon fractions (SARA), microalgal and bacterial density, and 
photosynthetic pigments were monitored, according to standardized methods. The mean values for organic matter removal (COD), TN and TP were $23.3 \pm 2.3,35.2 \pm 4.5$ and $64.6 \pm 4.8 \%$ for control; $27.6 \pm 1.64,79.8 \pm 2.05$ and $87.7 \pm 1.95 \%$ for $\mathrm{T} 1$; and $<0.1 ; 16.1 \pm 0.38$ and $44.7 \pm$ $1.18 \%$ for T2. The final concentrations of TPH were above the permissible limit of Venezuelan regulations for discharges into natural bodies of water; however, high rates of saturated and aromatic hydrocarbon removal (>70\%) were obtained, particularly in the bioaugmented treatment (T2). Autochthonous microbial consortia have great potential for the biorecovery of water at the Toas Island harbor, polluted by petroleum hydrocarbons. Therefore, it is advisable to continue researching into this treatment technology.

Keywords: bioaugmentation; biological treatment; biostimulation; hydrocarbons; microbial degradation; mixotrophic metabolism.

\section{INTRODUCCIÓN}

Los productos derivados del petróleo son la principal fuente de energía para la industria y diversas actividades de la vida cotidiana. Las fugas y derrames accidentales ocurren regularmente durante la exploración, producción, refinación, transporte y almacenamiento de petróleo, y productos petrolíferos [1]. Los hidrocarburos son considerados como contaminantes, cuyo tratamiento es de alta prioridad porque generan graves problemas ambientales, debido a su capacidad de solubilización en agua, toxicidad, naturaleza recalcitrante y potencial de bioacumulación [2]-[4].

La biodegradación es una tecnología viable de biorremediación para contaminantes orgánicos que emplea la versatilidad metabólica de los microorganismos con capacidad para descomponer contaminantes ambientales, en varias matrices y ambientes, con la subsecuente generación de metabolitos inofensivos o mineralización de los contaminantes en dióxido de carbono y agua [5]-[6].
La ruta metabólica común para el catabolismo de los hidrocarburos incluye la oxidación del grupo metilo originando un alcohol, el cual luego de una deshidrogenación, forma el ácido carboxílico correspondiente, que puede ser metabolizado por la ruta de $\beta$-oxidación de los ácidos grasos. Durante este proceso, los microorganismos ganan energía que pueden utilizar para sus funciones vitales, así como carbono [1], [7]-[8].

En los procesos de degradación un microorganismo puede descomponer sólo un número limitado de componentes del petróleo y es difícil encontrar microorganismos que puedan degradar completamente una mezcla de contaminantes [5],[9]. Por lo tanto, la construcción de consorcios microbianos es una alternativa innovadora para la eliminación de sustancias complejas y mezclas de contaminantes [4], [10]; este tipo de cooperación simbiótica entre bacterias heterotróficas y microalgas fototróficas, es la base para la eliminación de materia orgánica en las unidades de tratamiento de aguas residuales $\mathrm{y}$ 
puede ser usado para la remoción de contaminantes ambientales. El $\mathrm{O}_{2}$ producido por la fotosíntesis de las microalgas es utilizado por las bacterias para degradar la materia orgánica, mientras que el $\mathrm{CO}_{2}$ generado durante este proceso ayuda a completar el ciclo fotosintético [2], [11]-[12]. Además, las microalgas pueden servir como un hábitat para las bacterias, protegiéndolas de las condiciones ambientales adversas, consiguiendo así, aumentar el crecimiento bacteriano mediante la liberación de metabolitos extracelulares [12].

La biorremediación in situ es una técnica que permite eliminar, atenuar o transformar los compuestos contaminantes en la zona afectada, empleando la capacidad metabólica de los microorganismos (bacterias, hongos, levaduras y algas). La microbiota, frecuentemente asociada a los espacios contaminados (autóctona), reúne características ecológicas y metabólicas muy valiosas, puesto que son degradadores naturales de los compuestos xenobióticos presentes [8], [13]-15].

Entre las bacterias con mayor capacidad degradadora de hidrocarburos, se han reportado: Achromobacter, Acinetobacter, Arthrobacter, Azoarcus, Bacillus, Brevibacterium, Cellulomonas, Corynebacterium, Flavobacterium, Marinobacter, Mycobacterium, Micrococcus, Nocardia, Ochrobactrum, Pseudomonas, Rhodococcus, Sphingomonas, Stenotrophomonas, Vibrio, entre otras [1], [6], [8], [16], mientras que entre las microalgas destacan: Anabaena oryzae, Chlorella kessleri, Chlorella vulgaris, Chlorococcum sp., Pseudokirchneriella subcapitata, Scenedesmus platydiscus, Scenedesmus quadricauda, Selenastrum capricornutum y Stichococcus sp. [4], [10], [17].
Las microalgas también pueden aumentar el potencial de degradación en los consorcios microbianos, puesto que tienen la capacidad de crecer mixotróficamente (simultaneidad de metabolismo fotosintético y respiratorio) a bajas concentraciones de nutrientes y su tolerancia a circunstancias ambientales extremas puede ser una ventaja competitiva sobre microorganismos heterótrofos [4], [10], 18]-[21]. Adicionalmente, la estimulación de los microorganismos autótrofos mediante el aporte de nutrientes esenciales para incrementar su actividad microbiana (bioestimulación), y la introducción de cepas autóctonas o consorcios con las capacidades catalíticas deseadas (bioaumentación), permiten potenciar los procesos de degradación de los contaminantes [3], [22]-[27].

En el presente trabajo se evaluó la utilización de un consorcio microbiano autóctono (microalga-bacterias) para el tratamiento de aguas del puerto de Isla de Toas (Lago de Maracaibo, Venezuela) contaminadas con 1 $\% \mathrm{v} / \mathrm{v}$ de gasoil, con la finalidad de conocer su eficiencia en la remoción de materia orgáni$\mathrm{ca}$, hidrocarburos totales del petróleo (HTP), fracciones de hidrocarburos (SARA) y nutrientes ( $\mathrm{N}$ y P), mediante técnicas de bioestimulación y bioaumentación.

\section{MATERIALES Y MÉTODOS}

\section{1 Área de estudio y recolección de muestras}

La Isla de Toas está ubicada en la bahía El Tablazo, formando parte del municipio Almirante Padilla del estado Zulia, en el estuario Lago de Maracaibo (Venezuela); cubre un 
área aproximada de $3 \mathrm{Km}^{2}$, con una población de alrededor 9.000 habitantes, y situada a $10^{\circ} 57^{\prime} 00^{\prime \prime} \mathrm{N}$ y $71^{\circ} 40^{\prime} 00^{\prime \prime} \mathrm{O}$. En ella se encuentran las salinas de El Toro y Aracho, yacimientos de lignito sulfuroso y piedra caliza, arcillas de explotación en el sector sur y un pequeño yacimiento de mineral cuprífero. Sus riberas representan un hábitat propicio para el desarrollo de numerosas especies acuáticas y terrestres propias del lago, siendo aprovechadas también, para el turismo y la recreación.

En esta isla se localiza un puerto para el transporte marítimo de pequeñas embarcaciones de pesca comercial y actividades turísticas (ver fig. 1). Como resultado de estas actividades, diariamente se aprecian manchas de hidrocarburos en la superficie del agua adyacente a dicho puerto, lo que posiblemente puede provocar un efecto negativo sobre la biota acuática [2]-[4], [28], sin embargo esto no ha sido establecido hasta el momento.

En las inmediaciones del puerto se recolectaron muestras de agua superficial en recipientes plásticos de $18 \mathrm{~L}$, con ayuda de un recipiente previamente desinfectado con hipoclorito de sodio ( $5 \% \mathrm{v} / \mathrm{v}$ ) y un embudo. Los recipientes fueron trasladados inmediatamente al laboratorio para la caracterización fisicoquímica inicial y montaje de las unidades de tratamiento (microcosmos). Se realizaron mediciones in situ de temperatura, $\mathrm{pH}$ y salinidad, empleando una sonda multiparamétrica Orion.

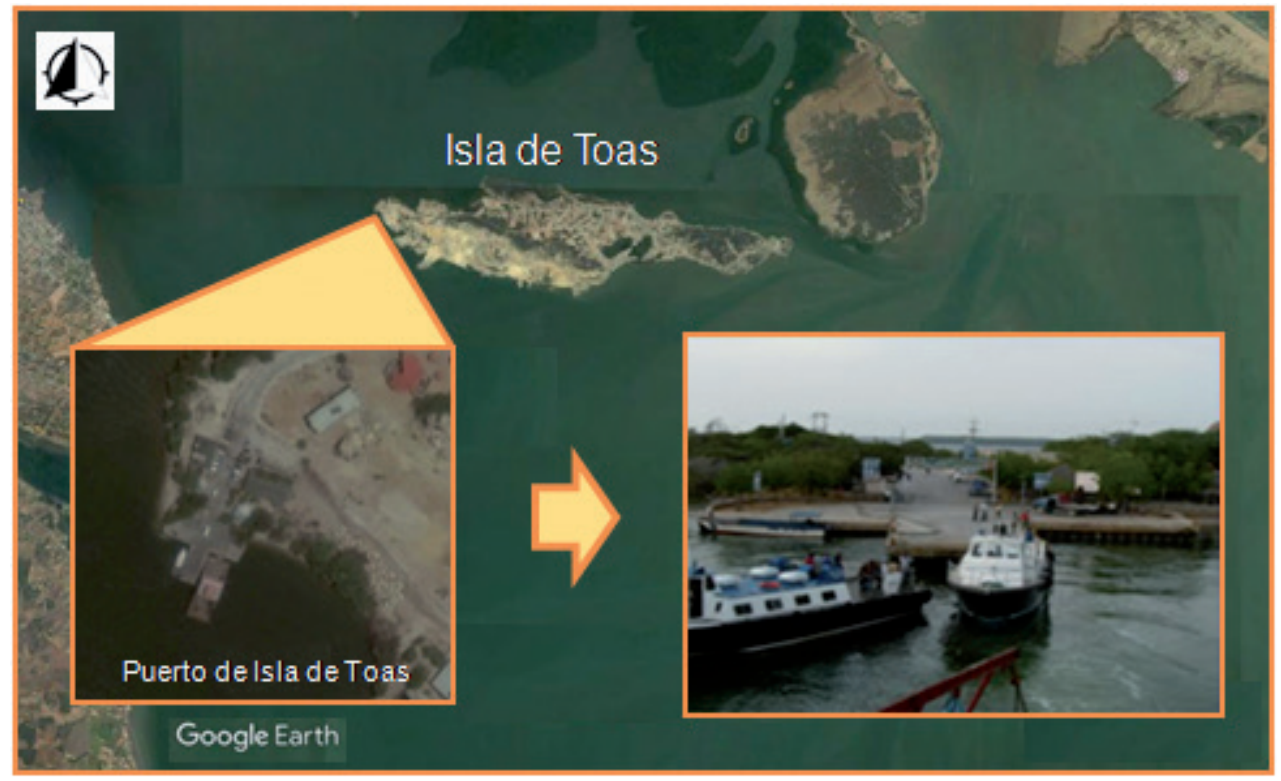

Figura 1. Ubicación del puerto de Isla de Toas, municipio Almirante Padilla, estado Zulia (Venezuela).

Fuente: modificado de Google Earth. 


\subsection{Ensayo de tratabilidad}

Se diseñó un ensayo de tratabilidad a escala de $20 \mathrm{~L}$, con dos tratamientos y un control, por triplicado. Las unidades de tratamiento (microcosmos) estuvieron constituidas por cajas plásticas rectangulares de color negro con capacidad de $49 \mathrm{~L}$ (9 unidades en total), desinfectadas previamenteconhipoclorito de sodio (5\% v/v), donde se dispusieron $20 \mathrm{~L}$ de agua del puerto contaminada experimentalmente al $1 \% \mathrm{v} / \mathrm{v}$ con gasoil, para garantizar la presencia de hidrocarburos durante el tratamiento. El agua fue prefiltrada (filtros convencionales de borosilicato) para minimizar la presencia de zooplancton. Un total de $180 \mathrm{~L}$ de agua se usaron para el montaje de las unidades experimentales (ver fig. 2).
En los tratamientos se aplicaron las estrategias de bioestimulación (T1) y bioaumentación (T2), mediante la inoculación de un consorcio microbiano autóctono (microalga-bacterias) al $20 \%$ v/v y fertilización con $0,25 \mathrm{~mL} / \mathrm{L}$ de Nitrofoska ${ }^{\odot}$. Estas proporciones fueron obtenidas en ensayos previos, bajo condiciones de laboratorio [29]. El control consistió en agua del sitio de estudio con $1 \% \mathrm{v} / \mathrm{v}$ de gasoil y sin complementos (ver tabla 1).

En todas las unidades se aplicó de igual manera: aireación mecánica y fotoperíodo luz:oscuridad de 12:12 h a 6 Klux, durante 70 días. La fertilización se realizó al inicio (día 0) y a los 35 días de tratamiento, a fin de garantizar la disponibilidad de nutrientes

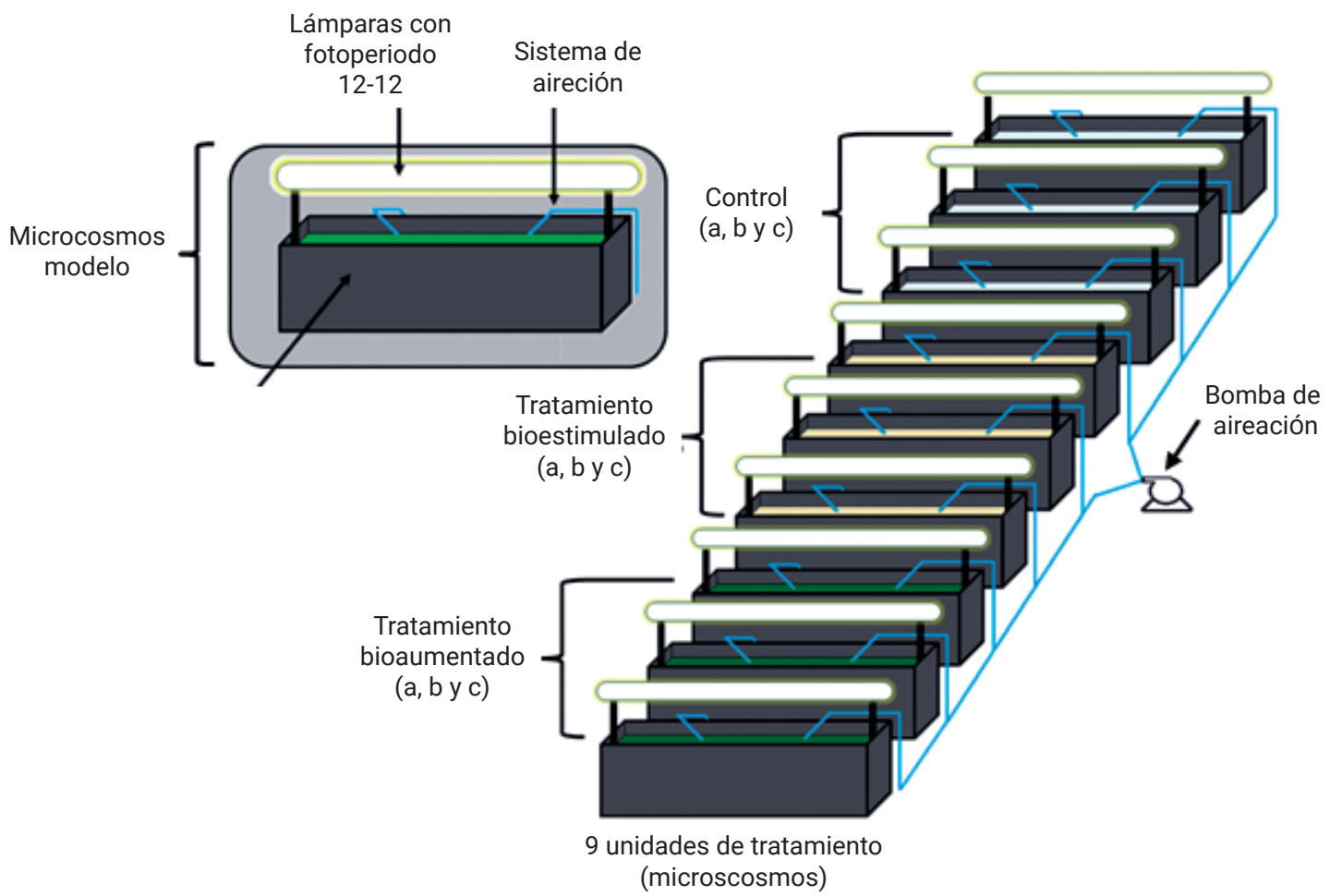

Figura 2. Diagrama de las unidades de tratamiento (microcosmos) usadas en el presente estudio. 
Tabla 1. Matriz experimental del estudio de tratabilidad con consorcio microbiano autóctono para agua superficial del puerto de Isla de Toas contaminada con $1 \% \mathrm{v} / \mathrm{v}$ de gasoil.

\begin{tabular}{|l|c|c|c|c|}
\hline \multicolumn{1}{|c|}{ Tratamiento } & $\begin{array}{c}\text { Agua de Isla } \\
\text { de Toas }\end{array}$ & $\begin{array}{c}\text { Gasoil 1 \% } \\
\text { v/v }\end{array}$ & $\begin{array}{c}\text { Fertilizante } \\
\mathbf{0 , 2 5} \mathbf{~ m L / L}\end{array}$ & $\begin{array}{c}\text { Consorcio } \\
\text { microbiano autóctono }\end{array}$ \\
\hline Control & $X$ & $X$ & & \\
\hline T1 - Tratamiento bioestimulado & $X$ & $X$ & $X$ & \\
\hline T2 - Tratamiento bioaumentado & $X$ & $X$ & $X$ & $X$ \\
\hline
\end{tabular}

inorgánicos para el crecimiento microbiano. Diariamente se controlaron las pérdidas de volumen por evaporación en las unidades experimentales, mediante la adición de agua destilada estéril.

\subsection{Seguimiento de las condiciones de tratamiento}

Durante los 70 días de ensayo se retiraron manualmente muestras de $250 \mathrm{~mL}$ de agua tratada cada 7 días, para el análisis de parámetros fisicoquímicos y microbiológicos en todos los microcosmos. Estas muestras fueron filtradas (filtros convencionales de borosilicato), para eliminar la interferencia debido a la presencia de microalgas.

Los parámetros fisicoquímicos analizados fueron: temperatura (termómetro convencional de mercurio), pH (método potenciométrico), demanda química de oxígeno (DQO) (método volumétrico con digestión en reflujo cerrado), nitrito (método colorimétrico estándar), nitrato (método de reducción en la columna de cadmio), nitrógeno total Kjeldahl (NTK) (método volumétrico), nitrógeno total (N-total) (NTK + nitrato + nitrito), ortofosfato (método colorimétrico del ácido vanadomolibdofosfórico), fósforo total (método colori- métrico del ácido vanadomolibdofosfórico, previa digestión ácida), de acuerdo con los métodos estandarizados [30]. Los hidrocarburos totales del petróleo (HTP) y las fracciones de hidrocarburos SARA (saturados, aromáticos, resinas y asfaltenos), se determinaron sólo al inicio y final del tratamiento por gravimétria [30].

En cuanto a los parámetros microbiológicos, se cuantificaron: densidad celular de la microalga, mediante observación directa al microscopio de campo claro [31]; bacterias heterótrofas aerobias, por la técnica de dilución en placas [30]-[31]; y pigmentos fotosintéticos (clorofila $a$, clorofila $b$, clorofila total y carotenoides), por espectrofotometría [32]-[33]. Adicionalmente, para la biomasa de Chlorella spp. se calcularon las velocidades de crecimiento $(\mu)$ y tiempos de duplicación (td), de acuerdo con las ecuaciones de Monod [34]-[35].

\subsection{Consorcio microbiano autóctono}

El consorcio microbiano autóctono $(10 \% \mathrm{mi}-$ croalga y $10 \%$ bacterias) estuvo conformado por un cultivo mixto de tres cepas bacterianas (Pseudomonas pertucinogena, Pseudomonas syringae y Sphingomonas paucimobilis), 
previamente aisladas e identificadas por Hernández [36], y un cultivo unialgal de Chlorella spp. $\left(2,5 \times 10^{6} \mathrm{cé} / \mathrm{mL}\right)$, con sus bacterias asociadas. Estos microorganismos fueron aislados de muestras de aguas del puerto de Isla de Toas y mantenidos bajo condiciones de laboratorio hasta su aplicación en los tratamientos.

\subsection{Análisis estadístico de datos}

Se realizó un análisis de varianza (ANOVA) de una vía, para estimar diferencias significativas entre el control y los tratamientos, en cuanto a los parámetros microbiológicos y fisicoquímicos monitoreados. Posteriormente, se aplicó una prueba Tukey a un nivel de significancia del $95 \%$, para determinar diferencias significativas entre los tratamientos.
Estos análisis se realizaron utilizando el programa SPSS 20.0 para Windows.

\section{RESULTADOS Y DISCUSIÓN}

\subsection{Características del agua superfi- cial del puerto}

En la tabla 2 se presentan los resultados de la caracterización fisicoquímica inicial del agua del puerto de Isla de Toas, antes del proceso de contaminación con gasoil. Los valores de HTP $(2.826,4 \pm 354,2 \mathrm{mg} / \mathrm{L})$ excedieron los límites permisibles (ausentes) para aguas marinas o de medios costeros, destinadas a la cría y explotación de moluscos consumidos en crudo (tipo 3), y para aguas destinadas a balnearios, deportes acuáticos, pesca

Tabla 2. Caracterización fisicoquímica inicial $(n=3)$ de agua superficial del puerto de Isla de Toas y límites permisibles de la normativa venezolana.

\begin{tabular}{|c|c|c|c|c|}
\hline Parámetro & $X \pm D E$ & Agua tipo $3^{a}$ & Agua tipo $4^{a}$ & $\begin{array}{c}\text { Descarga a } \\
\text { cuerpos de agua }^{\mathrm{a}}\end{array}$ \\
\hline Temperatura $\left({ }^{\circ} \mathrm{C}\right)$ & $31,3 \pm 0,2$ & - & - & c \\
\hline $\mathrm{pH}$ & $7,58 \pm 0,14$ & $6,5-8,5$ & $6,5-8,5$ & $6-9$ \\
\hline Salinidad (\%) & $4,5 \pm 0,3$ & - & - & - \\
\hline Nitrito (mg/L) & $0,012 \pm 0,002$ & - & - & $10 d$ \\
\hline Nitrato (mg/L) & $0,16 \pm 0,05$ & - & - & $10 d$ \\
\hline Nitrógeno total (mg/L) & $2,34 \pm 0,12$ & - & - & 40 \\
\hline Ortofosfato (mg/L) & $1,08 \pm 0,03$ & - & - & - \\
\hline Fósforo total (mg/L) & $1,36 \pm 0,04$ & - & - & 10 \\
\hline $\begin{array}{l}\text { Demanda química de } \\
\text { oxígeno }(\mathrm{mg} / \mathrm{L})\end{array}$ & $427,9 \pm 157,8$ & - & - & 350 \\
\hline $\begin{array}{l}\text { Hidrocarburos totales } \\
\text { del petróleo }(\mathrm{mg} / \mathrm{L})\end{array}$ & $2.826,4 \pm 354,2$ & Ausentes $^{\mathrm{b}}$ & Ausentes $^{b}$ & $20 \mathrm{e}$ \\
\hline
\end{tabular}

X: media aritmética, DE: desviación estándar, ${ }^{a}[37],{ }^{b}$ residuos de petróleo, ${ }^{\mathrm{c}}$ diferencia $<3^{\circ} \mathrm{C}$, dnitrito+nitrato, eaceites minerales e hidrocarburos, -: no presenta. 
deportiva, comercial y de subsistencia (tipo 4), así como también para la descarga a cuerpos de agua naturales $(20 \mathrm{mg} / \mathrm{L})$ [37]. De igual manera, el contenido de materia orgánica (medida como DQO) $(427,9 \pm 157,8 \mathrm{mg} / \mathrm{L})$, estuvo por encima de lo establecido por la legislación venezolana para el vertido a ecosistemas acuáticos naturales (350 mg/L) [37].

Esta caracterización inicial del agua del puerto justifica la aplicación de tecnologías de tratamiento para su adecuación a los requerimientos de la legislación, particularmente debido a los contenidos de materia orgánica e HTP (ver tabla 2).

\subsection{Tratamiento aplicando consorcio microbiano autóctono}

\subsubsection{Densidad microalgal}

El desenvolvimiento de la densidad microalgal en los microcosmos se muestra en la figura 3. No se observaron diferencias significativas entre el control y T1 (prueba de Tukey, $p>0,05)$, pero T2 difirió significativamente (prueba de Tukey, $p<0,05$ ) del control y T1.

El control exhibió una fase de adaptabilidad hasta el día 28 sin producción de biomasa (ver fig. 3A), la cual comenzó a incrementar del día 35 al $42(1,10 \pm 0,56 \times 104 \mathrm{cél} / \mathrm{mL})$, como resultado del suministro adicional de fertilizante. Luego de pequeñas fluctuaciones se obtuvo la mayor densidad de la microalga Chlorella spp. al final del ensayo (día 70), con una media aritmética de 2,96 $\pm 2,02 \times 10^{4}$ cél $/ \mathrm{mL}$.

En T1 no se presentó fase de adaptabilidad (ver fig. 3B), mostrando un aumento continuo en la densidad microalgal hasta el día 21, con una máxima exponencial de $2,51 \pm 1,06 \times 10^{6}$ cél/ $\mathrm{mL}$. Posteriormente, se inició la fase de declive hasta el día $63\left(5,02 \pm 0,84 \times 10^{5} \mathrm{cé} / \mathrm{mL}\right)$, para finalizar con un incremento de la biomasa hacia el día 70 de experimentación con 2,24 $\pm 1,31 \times 10^{6}$ cél/mL. Por su parte, el T2 mostró una fase de adaptación de 14 días (ver fig. 3C), para así iniciar el crecimiento exponencial hasta el día $42\left(2,01 \pm 1,04 \times 10^{6}\right.$ cél $\left./ \mathrm{mL}\right)$, favorecido por la segunda fertilización realizada en el día 35 . La mayor densidad de Chlorella spp. se reflejó a los 70 días con una media de 2,33 $\pm 2,08 \times 10^{6}$ cél/mL. Estos resultados aportan evidencia del proceso de adaptación de la microbiota
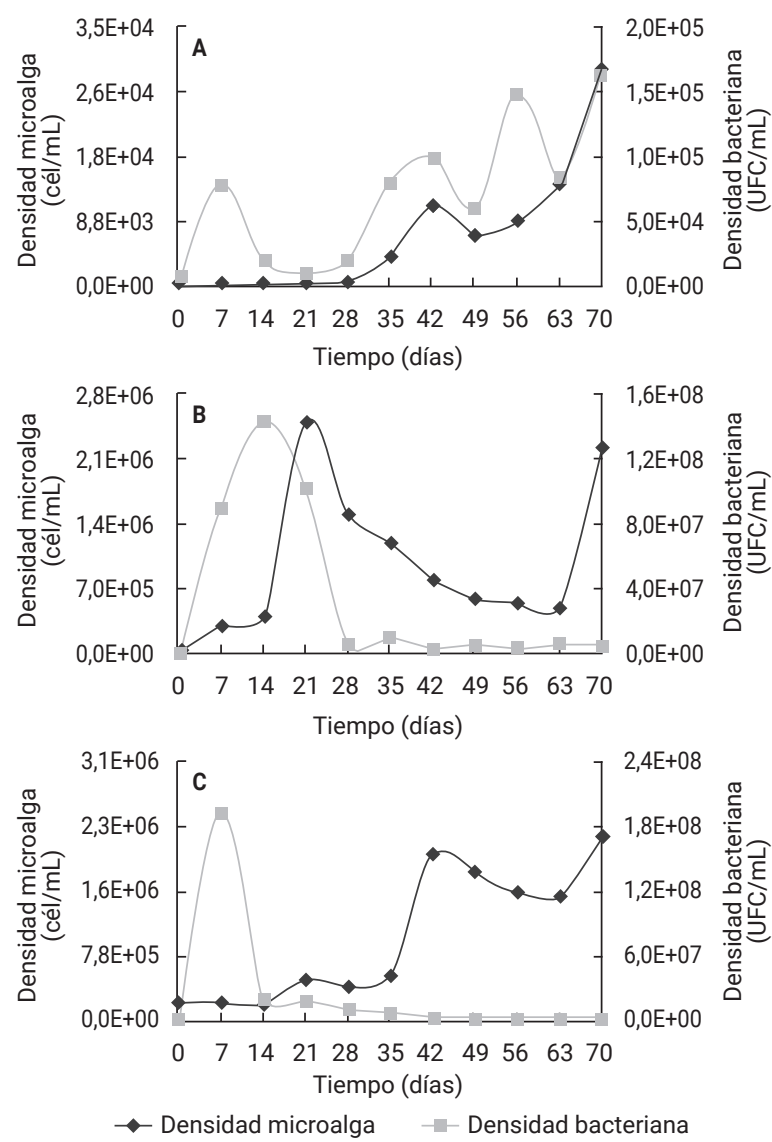

Figura 3. Densidad media de la microalga Chlorella spp. y densidad bacteriana durante el tratamiento de agua del puerto de Isla de Toas con consorcio microbiano autóctono. A) Control, B) Tratamiento bioestimulado (T1) y C) Tratamiento bioaumentado (T2). 
autóctona presente en las aguas adyacentes al puerto, en cuanto a la presencia de hidrocarburos, utilizándolos como fuentes de carbono y/o energía [4], [10], [17], [20].

En las unidades de estudio la media aritmética para la biomasa de la microalga Chlorella spp., fue la siguiente: T2 $\left(1,03 \pm 0,81 \times 10^{6}\right.$ cél $/ \mathrm{mL})>\mathrm{T} 1\left(1,64 \pm 8,10 \times 10^{5} \mathrm{cél} / \mathrm{mL}\right)>$ control $\left(6,98 \pm 8,97 \times 10^{3} \mathrm{cél} / \mathrm{mL}\right)$, mientras que las velocidades máximas de crecimiento fueron de: 0,$18 ; 0,26$; y $0,21 \mathrm{div} / \mathrm{d}$, con tiempos de duplicación celular de: 3,$76 ; 2,65$; y 3,34; respectivamente. No obstante, estos índices se pudieron ver subestimados por la aparición de organismos zooplanctónicos en las unidades experimentales, particularmente en T1 y T2. Al respecto, Esteves [38] indicó que la actividad de "pastoreo" del zooplancton herbívoro sobre el fitoplancton está caracterizada por el consumo de grandes cantidades de células vegetales, pudiendo disminuir grandemente la productividad primaria del sistema biológico.

Se ha reportado el efecto inhibidor de los hidrocarburos sobre las comunidades microalgales acuáticas, provocando una disminución del crecimiento y otras consecuencias sobre dichas poblaciones [23],[25],[28],[39]. Al respecto, Otero-Paternina et al. [28], observaron el efecto del hidrocarburo fenantreno sobre Chlorella vulgaris, en concentraciones de 1 hasta $10.000 \mu \mathrm{g} / \mathrm{L}$, obteniendo velocidades de crecimiento entre 2,7 y $6,7 \times 10^{5}$ cél/ $\mathrm{mL}$, las cuales resultan inferiores a las del presente estudio. No obstante, cuando se implementan consorcios microbianos autóctonos, este efecto de inhibición se contrarresta, generando un crecimiento microbiano a expensas de las fuentes de carbono presentes (mixotrofía) [10], [19]-[21], según lo observado en el presente trabajo (ver fig. 3).

\section{Pigmentos fotosintéticos}

Las concentraciones de pigmentos fotosintéticos (clorofila a, clorofila b, clorofila total y carotenoides), al igual que la densidad celular de Chlorella spp. del control, no mostraron diferencias significativas con respecto a $\mathrm{T} 1$ (prueba de Tukey, $p>0,05$ ), mientras que T2 difirió significativamente (prueba de Tukey, $\mathrm{p}<0,05)$ con respecto al control y T1.

La mayor producción de pigmentos fotosintéticos se obtuvo en T2 (ver tabla 3), con valores medios de clorofila total de $1,30 \pm 0,71$ $\mu \mathrm{g} / \mathrm{mL}$, mientras que el control exhibió las menores concentraciones $(0,10 \pm 0,07 \mu \mathrm{g} /$ $\mathrm{mL}$ ), como resultado de las estrategias de bioestimulación y bioaumentación en T1 y T2, respectivamente. De manera general, el desenvolvimiento de las concentraciones de pigmentos se correspondió con las tasas de crecimiento microalgal (ver fig. 3). También se evidenció un comportamiento análogo entre las concentraciones de clorofila total y las de carotenoides.

En contraste a los resultados del presente trabajo, Adoki [39] reportó una disminución de biomasa y contenido de clorofila durante bioensayos con microalgas autóctonas y el efluente procedente de una fábrica de fertilizantes nitrogenados, contaminado experimentalmente con petróleo (de 0,2 a $1 \%$ ) y sedimento de la misma industria. No obstante, en dicho estudio no se usaron las estrategias de bioestimulación y bioaumentación, lo que explica la diferencia en cuanto al desempeño de la comunidad microbiana. 
Tabla 3. Producción de pigmentos fotosintéticos (media aritmética \pm desviación estándar, para $n=3$ ) durante el tratamiento de agua del puerto de Isla de Toas con consorcio microbiano autóctono.

\begin{tabular}{|c|c|c|c|}
\hline Pigmentos $(\mu \mathrm{g} / \mathrm{mL})$ & Control & Bioestimulado $(\mathrm{T} 1)$ & Bioaumentado (T2) \\
\hline Clorofila $a$ & $0,04 \pm 0,03$ & $0,09 \pm 0,08$ & $0,93 \pm 0,51$ \\
\hline Clorofila $b$ & $0,06 \pm 0,04$ & $0,13 \pm 0,13$ & $0,38 \pm 0,21$ \\
\hline Clorofila total & $0,10 \pm 0,07$ & $0,22 \pm 0,21$ & $1,30 \pm 0,71$ \\
\hline Carotenoides & $0,05 \pm 0,03$ & $0,11 \pm 0,07$ & $0,42 \pm 0,23$ \\
\hline
\end{tabular}

Asimismo, El Fatah et al. [10] encontraron concentraciones de clorofila a: $0,67 \pm 0,02$; clorofila $b: \quad 1,09 \pm 0,10$ y carotenoides: $0,25 \pm 0,04 \mu \mathrm{g} / \mathrm{mL}$ a los 14 días de ensayo para un consorcio de Chlorella kessleri y Anabaena oryzae en cultivos tipo batch contaminados con $1 \%$ de petróleo, las cuales son comparables a los datos aquí presentados.

\subsubsection{Densidad bacteriana}

Las bacterias heterótrofas aerobias, asociadas a las unidades experimentales, tuvieron una densidad poblacional media de: $7,04 \pm 5,37 \times 10^{4} \mathrm{UFC} / \mathrm{mL}$ para el control, $3,38 \pm 5,20 \times 10^{7} \mathrm{UFC} / \mathrm{mL}$ para T1 y de $2,33 \pm 5,74 \times 10^{7} \mathrm{UFC} / \mathrm{mL}$ para T2. Estos dos últimos tratamientos no difirieron significativamente en ellos (prueba de Tukey, $p>0,05$ ), pero sí con respecto al control (prueba de Tukey, $p<0,05)$.

La dinámica poblacional bacteriana se ilustra en la figura 3 , donde destaca la ausencia de fase de latencia. En el control se observaron cuatro picos de alta densidad durante los días 7, 42, 56 y 70 (ver fig. 3A), para un valor máximo en este último día de $1,63 \pm 1,21 \times 10^{5} \mathrm{UFC} / \mathrm{mL}$. En T1 se denotó un sólo pico de máximo crecimiento du- rante el día 14 de ensayo (ver fig. 3B), con $1,44 \pm 1,06 \times 10^{8} \mathrm{UFC} / \mathrm{mL}$, al igual que T2 durante el día 7 (ver fig. 3C), con $1,95 \pm 1,11 \times 10^{8}$ $\mathrm{UFC} / \mathrm{mL}$. Estas diferencias de magnitud, entre el control y los tratamientos, resultan de la aplicación de biomasa y nutrientes, como estrategias para incrementar el metabolismo microbiano.

El desempeño del consorcio microbiano autóctono usado (microalga-bacterias), mostró cierta correspondencia en cuanto al desenvolvimiento de la dinámica poblacional microalgal vs. bacteriana (ver fig. 3), apreciándose inicialmente un incremento de la densidad de microalgas, a expensas del consumo de nutrientes inorgánicos (fertilizante), y subsecuentemente la de bacterias, ya que las primeras pueden aportar al medio: $\mathrm{O}_{2}$, exopolisacáridos, incluso fuentes de carbono bioacumuladas con antelación, sirviendo de soporte y nutrimentos a las bacterias heterótrofas presentes [2], [4], [10]-[12].

Díaz [40], trabajando con agua petrolizada de una fosa de almacenamiento de residuos líquidos, encontró cierta diversidad de grupos bacterianos heterótrofos, con recuentos de $2,67 \pm 0,43 \times 10^{7} \mathrm{UFC} / \mathrm{mL}$; valor ligeramente inferior a los encontrados en el presente estudio, debido probablemente a la presencia de 
derivados petroleros complejos en dicha fosa.

\subsubsection{Parámetros fisicoquímicos \\ pH}

Los valores de $\mathrm{pH}$ se mantuvieron relativamente estables cerca del rango de neutralidad, bajo todas las condiciones de ensayo, con una ligera disminución durante el día 14: 6,85 $\pm 0,25$ (control); $6,48 \pm 0,33$ (T1) y 6,67 $\pm 0,16$ (T2), con medias aritméticas de: 7,59 $\pm 0,21 ; 7,90 \pm 0,11 \mathrm{y}$ $7,65 \pm 0,15$, respectivamente. No se observaron diferencias significativas del $\mathrm{pH}$ entre las condiciones de tratamiento $(p>0,05)$. Estos valores garantizaron la supervivencia de una amplia variedad de microorganismos neutrófilos, capaces de participar en las reacciones de biodegradación de hidrocarburos [1], [5], [7]-[8], [14], [41].

Balba et al. [42] señalaron que la oxidación de los hidrocarburos produce ácidos grasos que son utilizados por las bacterias o liberados al medio. En tal caso, el pH del sistema disminuye, según lo observado en el día 14 de este ensayo. No obstante, estas variaciones de $\mathrm{pH}$ pueden amortiguarse por la alcalinidad disponible y deben monitorearse continuamente, ya que las propiedades fisicoquímicas del agua y la biodisponibilidad de los hidrocarburos juegan un papel determinante para una biorremediación exitosa [5], [8].

Los valores de $\mathrm{pH}$ en $\mathrm{T} 1$ y $\mathrm{T} 2$ cumplieron con lo establecido en la normativa venezolana para aguas tipo 3 y $4(6,5-8,5)$, así como para la descarga a cuerpos de agua naturales (69) [37].

Materia orgánica
Los microcosmos control, T1 y T2 reflejaron una disminución continua del contenido de materia orgánica (medida como DQO), durante el periodo de tratamiento (ver fig. 4A). Las concentraciones medias de DQO fueron de: $766,6 \pm 62,0 ; 678,1 \pm 90,4$ y $606,7 \pm 185,8$ $\mathrm{mg} / \mathrm{L}$, es decir: control > T1 > T2, con rangos de: $709,2 \pm 28,0-924,1 \pm 41,2 ; 556,3 \pm 22,3-$ $858,0 \pm 32,2$ y $313,1 \pm 36,5-884,4 \pm 71,1 \mathrm{mg} / \mathrm{L}$,
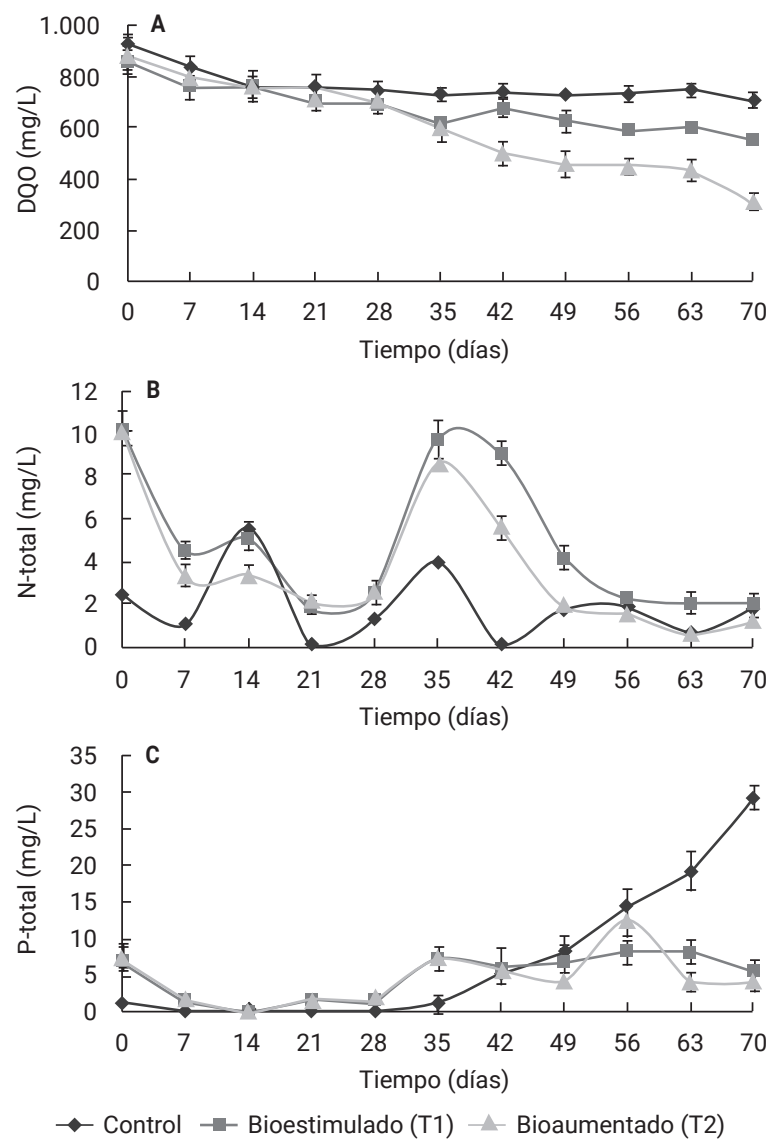

Figura 4. Variación de: A) Demanda química de oxígeno (DQO), B) Nitrógeno total (N-total) y C) Fósforo total (P-total) en las unidades experimentales, durante el tratamiento de agua del puerto de Isla de Toas con consorcio microbiano autóctono. Las barras verticales indican la media aritmética \pm desviación estándar para $n=3$. 
respectivamente. La prueba de Tukey mostró diferencias significativas (prueba de Tukey, $p<0,05$ ) entre el control y los tratamientos.

La mayor eficiencia de remoción de materia orgánica (DQ0) se obtuvo en T2 $(64,6 \pm$ $4,8 \%)$, seguido de T1 $(35,2 \pm 4,5 \%)$ y el control $(23,3 \pm 2,3 \%)$ (ver fig. 4). Las concentraciones finales (día 70) de DQO de T2 (ver fig. 4A; 313,1 $\pm 36,5 \mathrm{mg} / \mathrm{L}$ ), lograron cumplir con el límite de descarga establecido en la legislación venezolana, a cuerpos de agua naturales (350 mg/L) [37].

Los resultados son comparables a los reportados por Riaño et al. [43], con remociones de DQO soluble entre 29,0 y $59,2 \%$ para el tratamiento de efluentes de una industria procesadora de pescado, en fotobiorreactores inoculados con microalgas Spirulina platensis y Chlorella sorokiniana; en simbiosis con bacterias aerobias, siendo inferiores a los señalados por Mannina et al. [44], para aguas salinas sintéticas contaminadas con gasoil $(20 \mathrm{mg} / \mathrm{L})$, tratadas en una planta piloto provista de un biorreactor de membrana, con una remoción de DQO de 91 \%. Estas diferencias pueden deberse a la naturaleza propia del efluente en tratamiento y de los microorganismos involucrados.

Las remociones de materia orgánica obtenidas (ver fig. 4A) son indicativas de la utilización del carbono orgánico disponible (principalmente hidrocarburos), por parte de la comunidad microbiana presente para sus funciones metabólicas (ver fig. 3), con mayor proporción en T2 (consorcio microbiano autóctono). De esta manera, las bacterias obtienen carbono al mineralizar los sustratos orgánicos, mediante el consumo de oxígeno disuelto del sistema (metabolismo heterotrófico), mientras que las microalgas seguirían un metabolismo mixotrófico [10], [19]-[21].

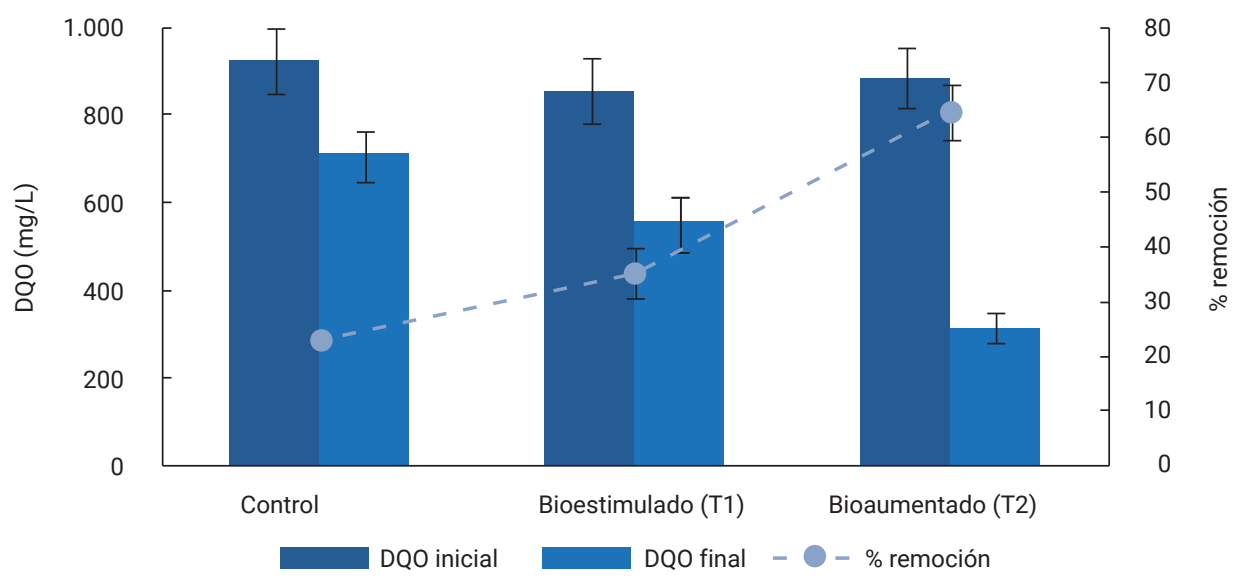

Figura 5. Contenido de materia orgánica (medido como DQO) en las unidades experimentales (inicial, final y $\%$ de remoción), durante el tratamiento de agua del puerto de Isla de Toas con consorcio microbiano autóctono. Las barras verticales indican la media aritmética \pm desviación estándar para $n=3$. 


\section{Nitrógeno}

Los niveles de nitrito se encontraron en los rangos de $0,013-0,118 \mathrm{mg} / \mathrm{L}$, para el control; de 0,011-0,044 mg/L, para T1; y de 0,013$0,069 \mathrm{mg} / \mathrm{L}$, para T2; cuyos valores mostraron diferencias significativas con respecto al control (prueba de Tukey, $p<0,05$ ). De manera general, las concentraciones de $\mathrm{NO}_{2}$ fueron estables y bajas en el periodo de estudio.

El nitrato, por su parte, exhibió rangos de concentraciones de 0,05-0,19;0,05-1,80; y de $0,05-1,45 \mathrm{mg} / \mathrm{L}$, para el control T1 y T2, respectivamente. Los tenores máximos en los tratamientos se obtuvieron en los días de fertilización con Nitrofoska ${ }^{\odot}$ (días 0 y 35 ), el cual contiene $\mathrm{N}$ bajo esta forma química, pero fue consumido rápidamente por la comunidad autótrofa presente, estimulando su crecimiento (ver fig. 3). Las concentraciones de $\mathrm{NO}_{3}$ en los tratamientos difirieron significativamente del control (prueba de Tukey, $p<0,05$ ), pero no entre ellos (prueba de Tukey, $p>0,05$ ).

Todas las concentraciones de nitrógeno inorgánico $\left(\mathrm{NO}_{2^{-}}+\mathrm{NO}_{3}\right)$ en los microcosmos, estuvieron por debajo del límite máximo permisible para la descarga a cuerpos de agua naturales, establecido en la norma ambiental venezolana (10 mg/L) [37].

El NTK presentó concentraciones medias de $1,76 \pm 1,61 \mathrm{mg} / \mathrm{L}$, para el control; $4,65 \pm 3,04$ $\mathrm{mg} / \mathrm{L}$, para $\mathrm{T} 1$; y de $3,52 \pm 2,87 \mathrm{mg} / \mathrm{L}$, para $\mathrm{T} 2$; como resultado de la activación del metabolismo microbiano, producto de las estrategias de fertilización e inoculación de biomasa ( $\mathrm{NTK}=\mathrm{NH}_{4^{+}}+\mathrm{N}$-orgánico) [37]. Por ello, se obtuvieron diferencias significativas de las concentraciones de los tratamientos con respecto al control (prueba de Tukey, $p<0,05$ ), pero no entre estos (prueba de Tukey, $p>0,05)$.

En la figura 4B se muestra la evolución temporal de las concentraciones de $\mathrm{N}$-total, en las unidades de experimentales. En el control se observaron ligeras fluctuaciones con valores máximos en los días $14(5,54 \pm 0,32$ $\mathrm{mg} / \mathrm{L})$ y $35(3,96 \pm 0,21 \mathrm{mg} / \mathrm{L})$, con una media aritmética de 1,90 $\pm 1,62 \mathrm{mg} / \mathrm{L}$. Para T1 y T2 se reflejaron las mismas tendencias de variación en las concentraciones, con tenores ligeramente superiores para $\mathrm{T} 1$, y picos más elevados durante los días 0 y 35 , resultantes de la fertilización e inoculación de biomasa, respectivamente. Las concentraciones de $\mathrm{N}$-total oscilaron entre $1,88 \pm 0,12$ y $10,25 \pm 0,82 \mathrm{mg} / \mathrm{L}$, para $T 1 ; y$ entre $0,63 \pm 0,08$ y $10,05 \pm 0,56 \mathrm{mg} / \mathrm{L}$, para $\mathrm{T} 2$. Al igual que el resto de las formas de $\mathrm{N}$ analizadas, el contenido de $\mathrm{N}$-total entre los tratamientos no fue significativamente diferente (prueba de Tukey, $p>0,05$ ), pero estos difirieron significativamente respecto al control (prueba de Tukey, p<0,05).

La dinámica del nitrógeno en los procesos de tratamiento biológico es un fenómeno complejo. El N-orgánico particulado se hidroliza abióticamente a N-orgánico soluble que es utilizado por bacterias heterotróficas y convertido en $\mathrm{NH}_{4}{ }^{+} \mathrm{El} \mathrm{NH}_{4^{+}}$sirve como fuente de $\mathrm{N}$ para la síntesis de nueva biomasa y como la única fuente de energía para el crecimiento de bacterias oxidantes de amonio; la producción de $\mathrm{NO}_{2}$-a partir de $\mathrm{NH}_{4}{ }^{+}$es llevada a cabo por estas bacterias. La siguiente etapa de oxidación para producir $\mathrm{NO}_{3}$ - es mediada por bacterias oxidantes de nitrito. La desnitrificación heterotrófica es un proceso secuencial que consta de cuatro 
pasos de reducción: $\mathrm{NO}_{3}$ - a $\mathrm{NO}_{2},-\mathrm{NO}, \mathrm{N}_{2} \mathrm{O}$ y $\mathrm{N}_{2}$ [45]-[46]. La simultaneidad de estas reacciones, rigieron la movilidad de las diferentes formas de $\mathrm{N}$ en las unidades de tratamiento (ver fig. 4B).

Se obtuvieron remociones medias de $\mathrm{N}$-total de: $27,6 \pm 1,64 ; 79,8 \pm 2,05$ y $87,7 \pm 1,95$ $\%$ para el control, T1 y T2, respectivamente. Estos valores son superiores a los reportados por Mannina et al. [44], para el tratamiento de aguas salinas sintéticas contaminadas con gasoil $(20 \mathrm{mg} / \mathrm{L})$ en una planta piloto provista de un biorreactor de membrana, con una remoción de $\mathrm{N}$-total de $53 \%$, lo cual puede ser adjudicado al efecto potenciador del metabolismo microbiano, como resultado de las estrategias de bioestimulación y bioaumentación.

Las concentraciones de N-total en el control y los tratamientos, cumplieron con la normativa de descarga a cuerpos de agua naturales establecida en Venezuela (40 mg/L) [37].

\section{Fósforo}

Las concentraciones medias de ortofosfato durante los ensayos se ubicaron en: $6,93 \pm 9,45 ; 4,05 \pm 2,50$ y $3,51 \pm 2,92 \mathrm{mg} / \mathrm{L}$, para el control T1 y T2, respectivamente, cuyo comportamiento en función del tiempo fue equivalente a la de P-total (ver fig. 4C). La prueba de Tukey indicó que existieron diferencias significativas de los tratamientos con respecto al control $(p<0,05)$, mientras que T1 y T2 no fueron estadísticamente distintos $(p>0,05)$.

La disponibilidad de ortofosfato proporcionó soporte al crecimiento autotrófico de las microalgas en los días subsiguientes a la adición de fertilizante. Notoriamente en el día 0 , para T1; y día 35 para control y T2 (ver fig. 3). El $\mathrm{PO}_{4}^{-3}$ se emplea como nutriente esencial en las actividades metabólicas y la síntesis de biomasa. Las células de microalgas absorben y almacenan $\mathrm{N}$ y $\mathrm{P}$ para la síntesis de proteínas, lípidos, adenosin trifosfato (ATP) y otras biomoléculas [12], [18].

Con relación a la variabilidad de P-total, en la figura $4 C$ se presentan sus concentraciones durante los ensayos. En el control los valores fluctuaron de $0,15 \pm 0,06$ a $29,32 \pm 1,56$ $\mathrm{mg} / \mathrm{L}$; en T1 de $0,22 \pm 0,08$ a $8,30 \pm 1,65 \mathrm{mg} / \mathrm{L}$; $y$ en T2 de 0,35 $\pm 0,07$ a $12,62 \pm 2,32 \mathrm{mg} / \mathrm{L}$. Durante los primeros 35 días se observó un comportamiento relativamente estable y similar para las tres condiciones de prueba. Posteriormente, el control experimentó un incremento progresivo hasta su máxima concentración en el día $70(29,32 \pm 1,56 \mathrm{mg} / \mathrm{L})$. En T1 se mantuvo una concentración media de $7,15 \pm 1,01 \mathrm{mg} / \mathrm{L}$, mientras que en T2 aumentó ligeramente en el día $56(12,62 \pm 2,32$ $\mathrm{mg} / \mathrm{L}$ ). No se detectaron diferencias significativas entre los tratamientos (prueba de Tukey, $p>0,05$ ), pero sí de estos con respecto al control (prueba de Tukey, $p<0,05)$, en cuanto a las concentraciones de P-total.

El aumento de las formas de $\mathrm{P}$ durante el tratamiento de aguas del puerto de Isla de Toas, particularmente en el control, puede estar relacionado con: 1) productos de excreción de organismos zooplanctónicos al consumir células microalgales [38], [47-48], y 2) mineralización de células muertas de microorganismos, que devuelven al medio sus constituyentes celulares como $\mathrm{N}$ y $\mathrm{P}$ [49]-[50], lo cual coincide con el desenvolvimiento de la 
comunidad microbiana de los microcosmos (menor densidad celular), particularmente hacia finales del periodo de experimentación (ver fig. 3).

Las remociones medias de P-total en el presente estudio fueron: control $<0,1 \%$; T1 $16,1 \pm 0,38 \%$; y T2 $44,7 \pm 1,18 \%$, las cuales mostraron un comportamiento similar al descrito por Venosa [51], quien señaló que las mayores disminuciones de fósforo en medios acuáticos contaminados con hidrocarburos, tenían lugar en las primeras semanas de estudio, disminuyendo de manera secuencial, pero en menor grado hasta el final del ensayo (ver fig. 4C). De igual manera, los resultados son comparables a los descritos por Mujtaba et al. [19], para un sistema de consorcio simbiótico en el tratamiento de un agua residual sintética. Estos investigadores observaron una alta tasa de eliminación de N, P y DQO, indicando que la capacidad de captación de nutrientes por Chlorella vulgaris se incrementó en presencia de la bacteria Pseudomonas putida, lo cual también se obtuvo en T2.

Díaz [40] determinó una remoción de P-total de $37,18 \%$ durante el tratamiento de los residuos líquidos de una fosa de almacenamiento de agua petrolizada, aplicando inóculo de microalgas (incluyendo bacterias asociadas), fertilización y un periodo de ensayo de 90-105 días. Por su parte, Pérez-García et al. [21] obtuvieron una remoción de $P$ de 31,5 \% en aguas residuales sintéticas, aplicando un consorcio de C. vulgaris y Azospirillum brasilense en un reactor cónico invertido. Estos resultados son inferiores a los encontrados en T2, por efecto de la bioaumentación con fertilización y adición de biomasa microbiana.
De manera general, las concentraciones de P-total en los tratamientos se ubicaron por debajo del límite máximo establecido en la normativa venezolana para la descarga a cuerpos de agua naturales (10 mg/L) [37], con excepción del día 56 en T2 (12,62 \2,32 $\mathrm{mg} / \mathrm{L}$ ) y en el control a partir del día 56 de ensayo (ver fig. 4C).

\section{Hidrocarburos}

En la tabla 4 se presentan las concentraciones iniciales y finales de las fracciones de hidrocarburos, así como las de HTP y sus porcentajes de remoción en las unidades de ensayo. La fracción de asfaltenos se presentó en niveles $<0,2 \mathrm{mg} / \mathrm{L}$, en todas las condiciones experimentales. Las concentraciones finales más bajas de hidrocarburos se observaron en $\mathrm{T} 2$.

El límite permisible de HTP establecido en la normativa ambiental venezolana para el vertido a cuerpos de agua naturales (20 $\mathrm{mg} / \mathrm{L}$ ) [37], no pudo alcanzarse bajo las condiciones establecidas en este estudio, por lo que el efluente tratado requiere de un tratamiento complementario para cumplir con dicha norma. No obstante, se obtuvieron altas tasas de biodegradación del gasoil añadido. Al respecto, las remociones de hidrocarburos saturados, aromáticos, resinas e HTP estuvieron entre 6,6 y $81,7 \%$ (ver fig. 5 , tabla 4). Se obtuvieron diferencias significativas (prueba de Tukey, $p<0,05$ ) para las remociones de hidrocarburos saturados, aromáticos e HTP, de los tratamientos con respecto al control, así como entre T1 y T2. Los niveles de resinas (compuestos recalcitrantes) no fueron significativamente diferentes $(p>0,05)$ para las condiciones de tratamiento. 
Tabla 4. Fracciones de hidrocarburos durante el tratamiento de agua del puerto de Isla de Toas contaminadas con $1 \% \mathrm{v} / \mathrm{v}$ de gasoil, usando consorcio microbiano autóctono.

\begin{tabular}{|c|c|c|c|c|}
\hline \multicolumn{1}{|c|}{ Hidrocarburos (mg/L) } & Control & Bioestimulado (T1) & Bioaumentado (T2) \\
\cline { 2 - 5 } Saturados & Inicial & $6.046,0 \pm 219,5$ & $6.083,3 \pm 241,7$ & $6.183,3 \pm 104,8$ \\
\cline { 2 - 5 } & Final & $4.292,3 \pm 97,7$ & $1.826,7 \pm 311,8$ & $1.266,7 \pm 51,3$ \\
\cline { 2 - 5 } & $\%$ remoción & $29,0 \pm 3,6$ & $70,0 \pm 4,5$ & $79,5 \pm 2,2$ \\
\hline \multirow{4}{*}{ Aromáticos } & Inicial & $2.310,3 \pm 80,6$ & $2.248,3 \pm 138,5$ & $2.124,3 \pm 89,7$ \\
\cline { 2 - 5 } & Final & $1.815,7 \pm 52,3$ & $948,3 \pm 93,8$ & $600,3 \pm 58,5$ \\
\cline { 2 - 5 } & \% remoción & $21,4 \pm 3,3$ & $57,8 \pm 4,6$ & $71,7 \pm 5,4$ \\
\hline \multirow{3}{*}{ Resinas } & Inicial & $33,3 \pm 1,5$ & $33,7 \pm 1,2$ & $32,2 \pm 0,1$ \\
\cline { 2 - 5 } & Final & $30,7 \pm 0,9$ & $27,8 \pm 0,6$ & $25,9 \pm 0,8$ \\
\cline { 2 - 5 } & \% remoción & $7,8 \pm 1,2$ & $17,5 \pm 3,6$ & $18,8 \pm 4,2$ \\
\hline \multirow{3}{*}{ HTP } & Inicial & $8.389,6 \pm 202,3$ & $8.365,3 \pm 218,4$ & $8.339,6 \pm 110,3$ \\
\cline { 2 - 5 } & Final & $6.138,7 \pm 84,2$ & $2.802,8 \pm 302,1$ & $1.892,9 \pm 42,1$ \\
\cline { 2 - 5 } & \% remoción & $26,8 \pm 1,6$ & $66,5 \pm 1,9$ & $77,3 \pm 2,8$ \\
\hline
\end{tabular}

HTP: hidrocarburos totales del petróleo. La fracción de asfaltenos se presentó en niveles <0,2 mg/L.

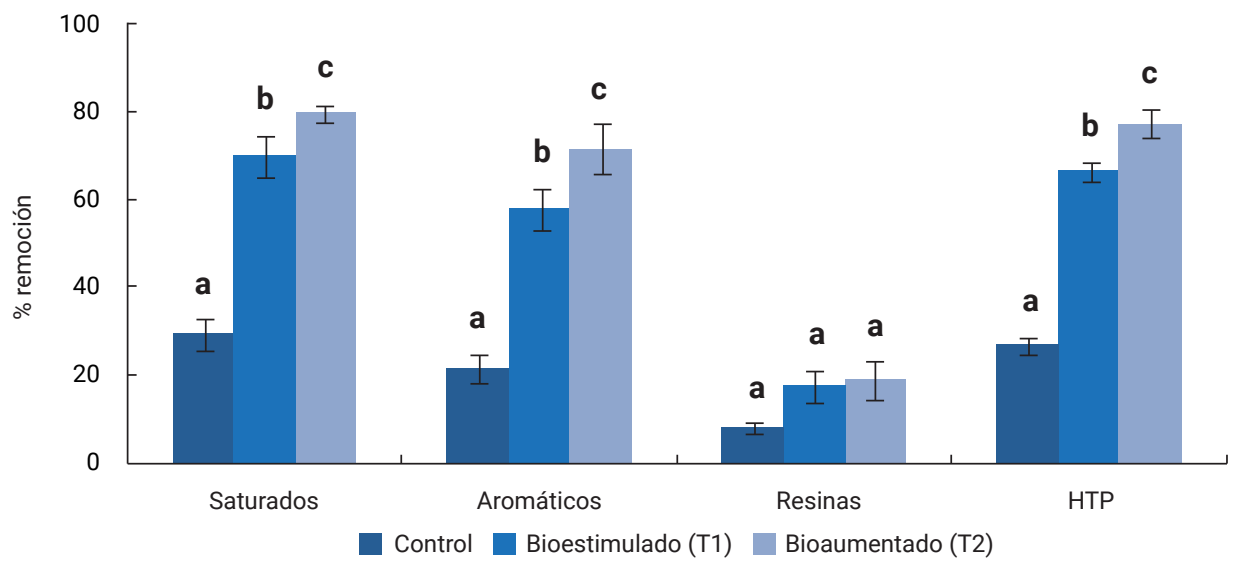

Figura 6. Remoción de las fracciones de hidrocarburos (SARA) e hidrocarburos totales del petróleo (HTP) durante el tratamiento de agua del puerto de Isla de Toas contaminadas con $1 \% \mathrm{v} / \mathrm{v}$ de gasoil, usando consorcio microbiano autóctono. La fracción de asfaltenos se presentó en niveles $<0,2 \mathrm{mg} / \mathrm{L}$. Las barras verticales indican la media aritmética \pm desviación estándar para $n=3$. Letras diferentes en una misma fracción indican diferencias significativas (prueba de Tukey, $p<0,05$ ). 
Estas diferencias resultaron del aumento de la productividad microbiológica (ver fig. 3), producido por la aplicación de las estrategias de bioestimulación y bioaumentación.

Muchos estudios han descrito la biodegradación de hidrocarburos por parte de comunidades microbianas [1], [4], [52]-[54], como base para los procesos de biorremediación de aguas y suelos impactados. Mittal y Singh [52] indicaron que la aplicación de consorcio bacteriano, nutrientes y factores ambientales resultó en 79,16 \% de eliminación de HTP en 60 días, en comparación con la remoción de sólo 30,24 \% llevada a cabo por microflora nativa. Similarmente, Hassanshahian et al. [23] reportaron que el uso de bioaumentación y consorcio bacteriano (A. borkumensis - Thalassolituus oleivorans) generó una degradación de $70 \%$ de petróleo crudo $(0,01 \%)$. Dichos datos son comparables a los obtenidos en el presente trabajo.

Finalmente, estos resultados demuestran la eficiencia del consorcio microbiano autóctono empleado, siendo capaz de degradar las fracciones de hidrocarburos del petróleo, presentes en el gasoil añadido (ver fig. 4A). Así, la cooperación entre microalgas fototróficas y bacterias heterotróficas mejora potencialmente la degradación de muchos contaminantes, incluyendo derivados del petróleo. Además, la selección adecuada de los microorganismos apropiados para conformar los consorcios, es de primordial importancia para garantizar el éxito y la eficiencia del proceso de degradación [2], [23].

\section{CONCLUSIONES Y RECOMENDA- CIONES}

El consorcio microbiano autóctono (Chlorella spp.-bacterias) fue capaz de utilizar la fuente de carbono disponible (gasoil al $1 \%$ $\mathrm{v} / \mathrm{v}$ ), con la subsecuente remoción de nutrientes ( $\mathrm{N}$ y $\mathrm{P}$ ); mostrando alto potencial de adaptabilidad y productividad durante el tratamiento de agua del puerto de Isla de Toas, con altos niveles de densidad celular y producción de pigmentos fotosintéticos. La eficiencia de remoción de materia orgánica (DQO e hidrocarburos), N y P, fue: tratamiento bioaumentado (T2) > tratamiento bioestimulado $(\mathrm{T} 1)>$ control.

Las concentraciones finales de materia orgánica (DQO), N-total y P-total cumplieron con los límites máximos permisibles de la legislación venezolana, para la descarga a cuerpos de aguas naturales. Los niveles finales de HTP estuvieron por encima del valor establecido, por lo cual es necesaria la aplicación de un tratamiento complementario del efluente, si bien se obtuvieron altas tasas de remoción de hidrocarburos saturados y aromáticos (>70\%), particularmente en el tratamiento bioaumentado (T2).

Para estudios futuros se recomienda el pretratamiento de las muestras de aguas naturales para remover la comunidad zooplanctónica presente, a fin de disminuir su poder depredador sobre las poblaciones microalgales, durante el tratamiento con consorcio microbiano autóctono.

\section{AGRADECIMIENTOS}

Al Observatorio Nacional de Ciencia, Tecnología e Innovación de Venezuela, por el financiamiento del proyecto Nro. 2011001259, del Programa de Estímulo a la Innovación e Investigación (PEII) y al Consejo de Desarrollo Científico, Humanístico y Tecnológico (CON- 
DES) de la Universidad del Zulia, por el financiamiento del proyecto Nro. CC-0592-14.

\section{REFERENCIAS}

[1] N. Das, y P. Chandran, "Microbial degradation of petroleum hydrocarbon contaminants: an overview," Biotechnology Research International, vol. 2011, pp. 1-13, 2011. https://doi. org/10.4061/2011/941810

[2] E. G. Omojevwe, y F. O. Ezekiel, "Microalgal-bacterial consortium in polyaromatic hydrocarbon degradation of petroleum - based effluent," Journal of Bioremediation \& Biodegradation, vol. 7(4), pp. 1-5, 2016.

[3] T. Sayara, E. Borràs, G. Caminal, M. Sarrà, y A. Sánchez, "Bioremediation of PAHs-contaminated soil through composting: Influence of bioaugmentation and biostimulation on contaminant biodegradation," International Biodeterioration \& Biodegradation, vol. 65, pp. 859-865, 2011. https://doi.org/10.1016/j.ibiod.2011.05.006

[4] S. R. Subashchandrabose, B. Ramakrishnan, M. Megharaj, K. Venkateswarlu, y R. Naidu, "Consortia of cyanobacteria/ microalgae and bacteria: biotechnological potential," Biotechnology Advances, vol. 29, pp. 896-907, 2011. https://doi. org/10.1016/j.biotechadv.2011.07.009

[5] M. Alexander. Biodegradation and Bio-

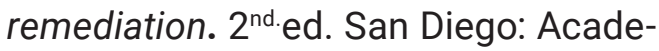
mic Press, p. 325, 1999.
[6] J. S. Seo, Y. S. Keum, y Q. X. Li, "Bacterial degradation of aromatic compounds," International Journal of Environmental Research and Public Health, vol. 6, pp. 278-309, 1999. https://doi.org/10.3390/ ijerph6010278

[7] F. Abbasian, R. Lockington, M. Mallavarapu, y R. Naidu, "A comprehensive review of aliphatic hydrocarbon biodegradation by bacteria," Applied Biochemistry and Biotechnology, vol. 176 (3), pp. 1-30, 2015. https://doi.org/10.1007/ s12010-015-1603-5

[8] S. Varjani, "Review: microbial degradation of petroleum hydrocarbons," Bioresource Technology, vol. 223, pp. 277-286, 2017. https://doi.org/10.1016/j.biortech. 2016.10.037

[9] J. R. Braggs, R. C. Prince, E. J. Harrier, y R. M. Atlas, "Atlas, effectiveness of bioremediation for the Exxon Valdez oil spiII," Nature, vol. 368, pp. 413-418, 1994. https://doi.org/10.1038/368413a0

[10] R. A. El Fatah, N. M. Sorour, y D. S. Yeheia, "Biodegradation of crude oil by Anabaena oryzae, Chlorella kessleri and its consortium under mixotrophic conditions," International Biodeterioration \& Biodegradation, vol. 112, pp. 128134, 2016. https://doi.org/10.1016/j. ibiod.2016.05.001

[11] M. Manzoor, R. Ma, H. A. Shakir, F. Tabssum, y J. I. Qazi, "Microalgal-bacterial consortium: a cost-effective approach of wastewater treatment in Pakistan," Punjab University Journal of Zoology, vol. 31(2), pp. 307-320, 2016. 
[12] A. L. Gonçalves, J. C. M. Pires, y M. Simões, "A review on the use of microalgal consortia for wastewater treatment," Algal Research, vol. 24, part B, 2017. En prensa. https://doi.org/10.1016/j.algal.2016.11.008

[13] Y. Barrios, "Biorremediación: una herramienta para el saneamiento de ecosistemas marinos contaminados con petróleo," Biotecnología Aplicada, vol. 28(2), pp. 60-68, 2011.

[14] V. L. Colin, L. B. Villegas, y C. M. Abate, "Indigenous microorganisms as potential bioremediators for environments contaminated with heavy metals," International Biodeterioration \& Biodegradation, vol. 69, pp. 28-37, 2012. https:// doi.org/10.1016/j.ibiod.2011.12.001

[15] N. Xu, M. Bao, P. Sun, y Y. Li, "Study on bioadsorption and biodegradation of petroleum hydrocarbons by a microbial consortium," Bioresource Technology, vol. 149, pp. 22-30, 2013. https://doi. org/10.1016/j.biortech.2013.09.024

[16] A. Mrozik, Z. Piotrowska-Seget, y S. Labuzek, "Bacterial degradation and bioremediation of polycyclic aromatic hydrocarbons," Polish Journal of Environmental Studies, vol. 12(1), pp. 15-25, 2003.

[17] A. P. Lei, Z. L. Hu, Y. S. Wong, y N. F. Tam, "Removal of fluoranthene and pyrene by different microalgal species," Bioresource Technology Journal, vol. 98(2), pp. 273-280, 2007. https://doi.org/10.1016/j.biortech.2006.01.012

[18] X. Zeng et al. "Bioprocess considerations for microalgal-based wastewater treatment and biomass production," Renewable and Sustainable Energy Reviews, vol. 42, pp.1385-1392, 2015. https://doi.org/10.1016/j.rser.2014.11.033

[19] G. Mujtaba, M. Rizwana, y K. Lee, "Removal of nutrients and COD from wastewater using symbiotic co-culture of bacterium Pseudomonas putida and immobilized microalga Chlorella vulgaris," Journal of Industrial and Engineering Chemistry, vol. 49, pp. 145-151, 2017. En prensa. https://doi.org/10.1016/j. jiec.2017.01.021

[20] H. A. Hamza, R. A. Hamouda, M. H. Husein, y S. S. Abd-Elwahid, "The characteristics of biomass production and lipid accumulation of Chlorella kessleri growth under mixotrophic and heterotrophic conditions," The Egyptian Journal of Experimental Biology (Botany), vol. 9, pp. 19-26, 2013.

[21] O. Pérez-García, L. E. De-Bashan, J. P. Hernández, and Y. Bashan, "Efficiency of growth and nutrient uptake from wastewater by heterotrophic, autotrophic, and mixotrophic cultivation of Chlorella vulgaris immobilized with Azospirillum brasilense," Journal of Phycology, vol. 46, pp. 800-812, 2010. https://doi.org/10.1111/j.1529-8817.2010.00862.x

[22] M. Andreolli, S. Lampis, P. Brignoli, and G. Vallini, "Bioaugmentation and biostimulation as strategies for the bioremediation of a burned woodland soil contaminated by toxic hydrocarbons: a comparative study," Journal of Environmental Management, vol. 153, pp. 121131, 2015. https://doi.org/10.1016/j.jenvman.2015.02.007 
[23] M. Hassanshahian, G. Emtiazi, G. Caruso, y S. Cappello, "Bioremediation (bioaugmentation/biostimulation) trials of oil polluted seawater: a mesocosm simulation study," Marine Environmental Research, vol. 95, pp. 28-38, 2014. https://doi.org/10.1016/j.marenvres.2013.12.010

[24] A. O. Olaniran, D. Pillay, y B. Pillay, "Biostimulation and bioaugmentation enhances aerobic biodegradation of dichloroethenes," Chemosphere, vol. 63, pp. 600-608, 2006. https://doi.org/10.1016/j.chemosphere.2005.08.027

[25] M. Nikolopoulou, N. Pasadakis, y N. Kalogerakis, "Evaluation of autochthonous bioaugmentation and biostimulation during microcosm-simulated oil spills," Marine Pollution Bulletin, vol. 72, pp. 165-173, 2013. https://doi.org/10.1016/j.marpolbul.2013.04.007

[26] M. Herrero, y D. C. Stuckey, "Bioaugmentation and its application in wastewater treatment: a review," Chemosphere, vol. 140, pp. 119-128, 2015. https://doi.org/10.1016/j.chemosphere.2014.10.033

[27] S. K. Shukla, N. Mangwani, T. S. Rao, y S. Das, "Chapter 8. Microbial Biodegradation and Bioremediation" in Biofilm-mediated bioremediation of polycyclic aromatic hydrocarbons, Oxford: Elsevier Inc., 2014, pp. 203-232. https:// doi.org/10.1016/B978-0-12-8000212.00008-X

[28] A. Otero-Paternina, P. E. Cruz-Casallas, y Y. M. Velasco-Santamaría, "Evaluación del efecto del hidrocarburo fenantreno sobre el crecimiento de Chlorella vulgaris (Chlorellaceae)," Acta Biológica Colombiana, vol. 18(1), pp. 87-98, 2013.
[29] D. Alburgue, L. Díaz-Borrego, J. Marín, y E. Morales, "Efecto de la bioestimulación y bioaumentación sobre la remoción de contaminantes en agua del puerto de Isla de Toas," Revista de la Facultad de Ingeniería U.C.V., vol. 31(3), pp. 17-26, 2017. En prensa.

[30] APHA, AWWA y WEF. Standard methods for the examination of water and wastewater. 21th edition. New York: American Public Health Association, 2005, p. 1427.

[31] G. Tortora, C. Funke y L. Case. Introducción a la microbiología, $9^{\text {na }}$ edición. Buenos Aires: Editorial Médica Panamericana S. A., 2007, p. 959.

[32] S. Jeffery, y G. Humphrey, "Nuevas ecuaciones espectrofotométricos para la determinación de clorofilas $a, b, c 1, y$ c2 en las plantas superiores, las algas y el fitoplancton natural," Biochemistry Physiology Pflanz, vol. 167, pp. 191-198, 1975.

[33] J. Strickland y T. Parsons, "A manual of sea water analysis," Canada Fisheries Research Board Bulletin, vol. 167, pp. 310-315, 1972.

[34] R. M. Maier. "Bacterial Growth," Chapter 3. in Environmental Microbiology, Part 1, Review of Basic Microbiological Concepts. Amsterdam: Academic Press. Inc., pp. 37-54, 2009. https://doi.org/10.1016/ B978-0-12-370519-8.00003-1

[35] G. C. Okpokwasili, y C. O. Nweke, "Microbial growth and substrate utilization kinetics," African Journal of Biotechnology, vol. 5(4), pp. 305-317, 2005. 
[36] D. Hernández, "Biodegradación de gasoil por bacterias aisladas de agua contaminada con hidrocarburos en Isla de Toas, estado Zulia" Trabajo Especial de Grado Facultad Experimental de Ciencias, Universidad del Zulia, Maracaibo, Venezuela, 2014, p. 86.

[37] Decreto 883. "Normas para la clasificación y el control de la calidad de los cuerpos de agua y vertidos o efluentes líquidos". Gaceta Oficial de la República Bolivariana de Venezuela No 5.021 . Caracas, 1995.

[38] F. Esteves. Fundamentos de limnologia. $2^{\mathrm{a}}$ ed. Rio de Janeiro: Intenciência, 1998, p. 226.

[39] A. Adoki, "Response of microalgae from mud-flats to petroleum hydrocarbons in the presence of nitrogenous fertilizer effluents," African Journal of Biotechnology, vol. 7(5), pp. 622-630, 2008.

[40] L. Díaz, "Crecimiento de microalgas y bacterias asociadas provenientes de una fosa petrolera en presencia de queroseno y su efecto en la producción de pigmentos y composición bioquímica microalgal", Trabajo de Ascenso, Facultad Experimental de Ciencias, Universidad del Zulia, Maracaibo, 2012, p. 96.

[41] M. Madigan, J. Martinko, y J. Parker. Brock: Biología de los microorganismos. $10^{\mathrm{a}}$ ed., Madrid: Pearson Prentice Hall, 2003, p. 1089.

[42] M. Balba, N. Al-Awadhi, y R. Al-Daher, "Bioremediation of oil-contaminated soil: microbiological methods for feasibility assessment and field evaluation," Journal of Microbiological Methods, vol. 32, pp. 155-164, 1998. https://doi.
org/10.1016/S0167-7012(98)00020-7

[43] B. Riaño, D. Hernández, y M. C. GarcíaGonzález, "Microalgal-based systems for wastewater treatment: Effect of applied organic and nutrient loading rate on biomass composition," Ecological Engineering, vol. 49, pp.112-117, 2012. https:// doi.org/10.1016/j.ecoleng.2012.08.021

[44] G. Mannina, A. Cosenza, D. Di Trapani, M. Capodici, y G. Viviani, "Membrane bioreactors for treatment of saline wastewater contaminated by hydrocarbons (diesel fuel): an experimental pilot plant case study," Chemical Engineering Journal, vol. 291, pp. 269-278, 2016. https:// doi.org/10.1016/j.cej.2016.01.107

[45] M. R. Beylier et al. "Biological nitrogen removal from domestic wastewater." $2^{\text {da }}$ ed. Reference Module in Earth Systems and Environmental Sciences, from Comprehensive Biotechnology, vol. 6, pp. 329-340, 2011.

[46] I. Schmidt et al. "New concepts of microbial treatment processes for the nitrogen removal in wastewater," FEMS Microbiology Reviews, vol. 27, pp. 481492, 2003. https://doi.org/10.1016/ S0168-6445(03)00039-1

[47] V. Montemezzani, I. C. Duggan, I. D. Hogg, y R. J. Craggs, "A review of potential methods for zooplankton control in wastewater treatment high rate algal ponds and algal production raceways," Algal Research, vol. 11, pp. 211226, 2015. https://doi.org/10.1016/j. algal.2015.06.024 
[48] Y. Si-Zhong et al. "Bioremediation of oil spills in cold environments: a review," Pedosphere, vol. 19(3), pp. 371-381, 2009. https://doi.org/10.1016/S10020160(09)60128-4

[49] C. Riquelme, y R. Avendaño, "Interacción bacteria-microalga en el ambiente marino y uso potencial en acuicultura," Revista Chilena de Historia Natural, vol. 76, pp. 725-736, 2003. https://doi.org/10.4067/S0716078X2003000400014

[50] R. Abed y J. Koster, "The direct role of aerobic heterotrophic bacteria associated with cyanobacteria in the degradation of oil compounds," International Biodeterioration \& Biodegradation, vol. 55, pp. 29-37, 2005. https://doi. org/10.1016/j.ibiod.2004.07.001

[51] A. Venosa, "Bioremediation treatability trials using nutrient application to enhance cleanup of oil contaminated shoreline", in Proceedings of $83^{\text {rd }}$. Air and Waste Management Association Annual Meeting in Pittsburg, pp. 90-92, 1990.
[52] A. Mittal, y P. Singh, "Polycyclic aromatic hydrocarbon degradation by developed consortium in microcosms study," The Internet Journal of Microbiology, vol. 7(1), pp. 1-8, 2009.

[53] M. A. Clarkson, y Al. Abubakar, "Bioremediation and biodegradation of hydrocarbon contaminated soils: a review," IOSR Journal of Environmental Science, Toxicology and Food Technology, vol. 9(11), pp. 38-45, 2015.

[54] Jahangeer, y V. Kumar, "An overview on microbial degradation of petroleum hydrocarbon contaminants," International Journal of Engineering and Technical Research, vol. 1(8), pp. 34-37, 2013. 
